\title{
Quality Assessment for AEW Based on Projection Pursuit Method
}

\author{
DONG Yu-cai ${ }^{1, a}$, DU Jian ${ }^{2, b^{*}}$, and Li Huizheng ${ }^{3, c}$ \\ ${ }^{1}$ Department of Fundament Academy of Armored Force Engineering Beijing 100072, China \\ 2 Department of Fundament Academy of Armored Force Engineering Beijing 100072, China \\ ${ }^{3}$ Department of Fundament Academy of Armored Force Engineering Beijing 100072, China

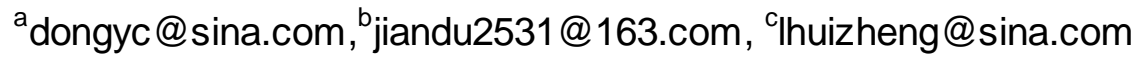

\begin{abstract}
Keywords: Early Warning Airplane(AEW);Projection Pursuit Method; Quality assessment Abstract.The projection pursuit method transforms the operational effectiveness index of Early Warning Airplane into one-dimensional projection value,giving the operational effectiveness order of AEW, and geting the weight of each performance index. The method is strong objectivity, it is of great significance for scientific evaluation and effective management of AEW operational effectiveness.
\end{abstract}

\section{Introduction}

With the rapid development of the advanced technology in military equipment,Early Warning Airplane(AEW) will become indispensable weapons in modern warfare,so it is particularly important research on the AEW operational effectiveness.Many scholars have explored the effectiveness evaluation methods of $\mathrm{AEW}^{[1-3]}$.In Literature ${ }^{[1]}$ the evaluation model of the AEW operational effectiveness was proposed as the basic framework for the American Weapon System Effectiveness Industry Advisory Committee (WSEIAC), On the basis of the analysis for the AEW operational effectiveness index system. The paper made the evaluation mathematical method of the AEW operational effectiveness,finally this paper introduced the application of the model formula by an example in the practice, verified the correctness and rigor of this formula.

According to the systematicness of the operational effectiveness evaluation and the uncertainty problem of assessment data, on the basis of operational effectiveness evaluation index system for AEW, the literature ${ }^{[2]}$ established the assessment model of operational effectiveness for AEW based on superiority function and AHP, and analyzed the operational effectiveness of AEW responsible for electronic countermeasures mission by using this model.

The literature ${ }^{[3]}$ established the evaluation index system of operational effectiveness for AEW,proposed the power operation law of interval number,determined the weights of qualitative index in the index system by interval number eigenvector method.By using the combination weighting method with the interval number eigenvector method and information entropy method to determine the weight of quantitative indicators in the index system, given the standardization method of the quantitative index and qualitative index in the index system,proposed the index polymerization method with weighted in the form of interval number and weighting product relation.

The literature ${ }^{[4]}$ established the evaluation index system of AEW according to the function and structure relationship, according to the operational effectiveness evaluation of multi index and uncertainty characteristics for AEW,establish a multilayer evaluation of AEW operational effectiveness model of fuzzy comprehensive evaluation combined with the fuzzy comprehensive evaluation method, verified the correctness and validity of the model by an example.

Projection pursuit method ${ }^{[5]}$ is proposed as an exploratory analysis, and also for clustering and classification methods of certainty analysis by Friedman and Turkey in 1974.Its essence is to observe the data from different angles, looking for the method can best reflect the characteristics of the data and most can develop the optimal projection method of data information.

Projection pursuit method is used to the reduction dimensionality technology of high-dimensional data analysis, it is suitable to analysis and process high dimension,non-linear,non normal problem. The evaluation results accord with the actual rate highly, it has been widely used in the water quality evaluation, the disaster 
assessment, the industrial economyand and the enterprise competitivenessetc ${ }^{[6-7]}$.In this paper,the projection pursuit technique is apply to evaluate operational effectiveness of AEW.

\section{The projection pursuit method ${ }^{[8]}$}

The sample evaluation index normalize process

The calculation formula is as follows

$$
x(i, j)=\frac{x^{*}(i, j)-x \min (j)}{x \max (j)-x \min (j)}
$$

In the formula, $x^{*}(i, j), i=1, \cdots, n ; j=1, \cdots, p$ present the $j$ th evaluation indexes for the for the $i$ th

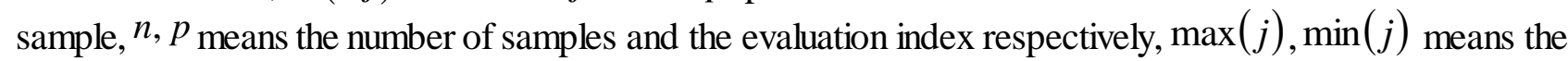
minimum and maximum values of the $j$ the evaluation index respectively in samples.

Construct the projection objective function

Objective function $Q(a)$. The essence is the $p$ dimensional data $x(i, j), j=1, \cdots, p$ is integrated into $a=(a(1), a(2), \cdots, a(p))$

It means one dimension projection value $z(i)$ for projection direction. The calculating formula is as follows

$$
z(i)=\sum_{i=1}^{n} a(j) x(i, j), \quad i=1, \cdots, p
$$

In the formula, $a$ is the unit length vector.

In the comprehensive projection value, the distribution characteristics of projection values $z(i)$ should be the local projection point as dense as possible, it best condensed into the plurality point group, and among the whole projection point group spread out as much as possible. Based on this, the function of projection indexes can be constructed to as follows

$$
Q(a)=S_{z} D_{z}
$$

In the formula, $S_{z}$ stand for the standard deviation of projection value $z(i), D_{z}$ stand for the local density of projection value $z(i)$. The calculation formula as follow

$$
\begin{aligned}
& S_{z}=\sqrt{\sum_{i=1}^{n} z(i)-\bar{z} /(n-1)} \\
& D_{z}=\sum_{i=1}^{n} \sum_{j=1}^{n}\left(R-r_{i j}\right) u\left(R-r_{i j}\right) \\
& r_{i j}=|z(i)-z(j)|
\end{aligned}
$$

In the formula, $\bar{z}$ stand for the series mean of $z(i), i=1, \cdots, n, R$ stand for the window radius of local density, $u_{t}$ stand for the unit step function, when $t=\left(R-r_{i j}\right) \geq 0$, the function value is 1 , when $t<0$, the function value is 0 . The local density window radius value $R$ demand the average number of the projection point in the window not too little, to avoid deviation is too big for moving average, but also it can't increase too high with the increase of index number $n$, then it can take $0.1,0.01,0.001$, etc.

To evaluate the best projection direction

By solving projection index function maximum, for indicating certain the characteristics of high-dimensional data possibly. The calculation formula as follow 


$$
\begin{aligned}
& \max Q(' a)=S_{z} D_{z} \\
& \text { s.t. } \quad \sum_{j=1}^{p} a^{2}(j)=1, \quad a(j) \geq 0
\end{aligned}
$$

The above formula is a complex nonlinear optimization problems as $a(j), j=1, \cdots, p$ for optimization variables. Projection index function optimization problem is the key to success for the application of projection pursuit method, and it has a considerable amount of calculation. In this paper, using the simplex method can effectively solve the constrained global optimization problem.

According to the optimization get $a^{*}$,generating into the formula $z(i)=\sum_{i=1}^{n} a(j) x(i, j)$,calculating the projection value of each evaluation samples quickly. By the numerical sequence from high to low, on the basis of the sequence to evaluate the index sample set.Optimization to get the optimal projection direction vector $a^{*}$ to reflect the different importance of various factors, and satisfied $a^{* 2}=1$, therefore $\omega=\left(a(1)^{2}, a(2)^{2}, \cdots, a(m)^{2}\right)$ can be as the weight of each influence factor.

\section{Air Early Warning(AEW) operational effectiveness evaluation}

Air Early Warning(AEW) operational effectiveness evaluation index and sample[9-10]

Establishing the index system for efficiency evaluation is a prerequisite for the effectiveness evaluation. There are numerous the factors influencing the AEW combat efficiency, this article selects the closest relations with AEW operational effectiveness as follows, the max-endurance time $\left(\mathrm{T}_{\text {endurance }}\right) \mathrm{h}$, the cruise speed $\left(\mathrm{V}_{\text {cruise }}\right) /(\mathrm{km} / \mathrm{h})$, dispatch out time $\left(\mathrm{T}_{\text {dispatch }}\right) / \mathrm{h}$ again.

The requirements level on the $\operatorname{airport}\left(\mathrm{K}_{\text {airport }}\right)$, the maximum detection of $\operatorname{radar}\left(\mathrm{L}_{\mathrm{radar}}\right) /(\mathrm{km})$, the total azimuth of $\operatorname{radar} \operatorname{search}\left(\theta_{\text {search }}\right) /($ degree $)$, the number of guide the aircraft to combat $\left(\mathrm{n}_{\text {guide }}\right)$, the radar $\operatorname{system}\left(\mathrm{K}_{\text {system }}\right)$,the capability of electronic reconnaissance(KESM), the ability of communication data exchange, the capacity of navigation and positioning, the ability of self-defense,etc.

As an example, evaluation the four types of AEW operational effectiveness on E-3F, E-2C in American,A-50 in Russia and Phalcon in Israel. Related technical indexes of four types of AWACS and capability index such as shown in table 1 .

\begin{tabular}{|c|c|c|c|c|}
\hline The evaluation index $\backslash$ model & E-3F & E-2C & A-50 & Phalcon \\
\hline the max-endurance time $\left(\mathrm{T}_{\text {endurance }}\right) / \mathrm{h}$ & 13 & 6.25 & 8.0 & 11.5 \\
\hline the cruise speed $\left(\mathrm{V}_{\text {cruise }}\right) /(\mathrm{km} / \mathrm{h})$ & 850 & 480 & 750 & 860 \\
\hline dispatch out time again $\left(\mathrm{T}_{\text {dispatch }}\right) / \mathrm{h}$ & 3 & 2 & 4 & 4 \\
\hline $\begin{array}{l}\text { the requirements level on the airport } \\
\left(\mathrm{K}_{\text {airport }}\right)\end{array}$ & 0.8 & 1.0 & 0.9 & 0.8 \\
\hline $\begin{array}{l}\text { the maximum detection of radar } \\
\left(\mathrm{L}_{\mathrm{radar}}\right) /(\mathrm{km})\end{array}$ & 370 & 408 & 360 & 260 \\
\hline the total azimuth of radar search $\left(\theta_{\text {search }}\right) /($ degree & 360 & 360 & 360 & 260 \\
\hline the number of guide the aircraft to combat $\left(\mathrm{n}_{\text {guide }}\right)$ & $\begin{array}{l}\text { 18/70(AUT } \\
\text { O) }\end{array}$ & 6 & $12 \sim 14$ & 14 \\
\hline the radar system $\left(K_{\text {system }}\right)$ & 0.9 & 0.7 & 0.8 & 1.0 \\
\hline the capability of electronic reconnaissance(KESM & 1.0 & 0.7 & 0.9 & 0.8 \\
\hline the ability of communication data exchange & 1.0 & 0.9 & 0.9 & 0.8 \\
\hline the capacity of navigation and positioning & 1.0 & 0.8 & 0.9 & 0.9 \\
\hline the ability of self-defense & 0.8 & 0.7 & 0.8 & 0.8 \\
\hline
\end{tabular}

\section{TABLE1 RELATED TECHNICAL INDEXES OF FOUR TYPES OF AWACS AND CAPABILITY INDEX}

comprehensive evaluation the combat effectiveness on AWE 
Density threshold is 0.1 , the calculation of each evaluation index the optimal projection direction and weight coefficient are shown in table 2.

Table 2 each evaluation index the optimal projection direction and weight coefficient

\begin{tabular}{|c|c|c|}
\hline evaluation index & $\begin{array}{l}\text { projection } \\
\text { direction }\end{array}$ & $\begin{array}{l}\text { weight } \\
\text { coefficient }\end{array}$ \\
\hline $\begin{array}{l}\text { the max-endurance } \\
\text { time }\left(\mathrm{T}_{\text {endurance }}\right) \mathrm{h}\end{array}$ & 0.3664 & 0.1343 \\
\hline the cruise speed $\left(\mathrm{V}_{\text {cruise }}\right) /(\mathrm{km} / \mathrm{h})$ & 0.3588 & 0.1288 \\
\hline dispatch out time again $\left(\mathrm{T}_{\text {dispatch }}\right.$ & 0.0004 & 0.0000 \\
\hline $\begin{array}{l}\text { the requirements level on the } \\
\text { airport }\end{array}$ & 0.4033 & 0.1626 \\
\hline$\left(\mathrm{K}_{\text {airport }}\right)$ & & \\
\hline $\begin{array}{l}\text { the maximum detection of } \\
\operatorname{radar}\left(\mathrm{L}_{\text {radar }}\right) /(\mathrm{km})\end{array}$ & 0.0016 & 0.0000 \\
\hline $\begin{array}{l}\text { the total azimuth of radar searc } \\
\left(\theta_{\text {search }}\right) /(\text { degree })\end{array}$ & 0.0004 & 0.0000 \\
\hline $\begin{array}{l}\text { the number of guide the aircraft } \\
\operatorname{combat}\left(\mathrm{n}_{\text {guide }}\right)\end{array}$ & 0.3191 & 0.1018 \\
\hline the radar system $\left(\mathrm{K}_{\text {system }}\right)$ & 0.3043 & 0.0926 \\
\hline $\begin{array}{l}\text { the capability of electronic } \\
\text { reconnaissance(KESM) }\end{array}$ & 0.2823 & 0.0797 \\
\hline $\begin{array}{l}\text { the ability of communication } d \varepsilon \\
\text { exchange }\end{array}$ & 0.0391 & 0.0015 \\
\hline $\begin{array}{l}\text { the capacity of navigation and } \\
\text { positioning }\end{array}$ & 0.3216 & 0.1034 \\
\hline the ability of self-defense & 0.4419 & 0.1953 \\
\hline
\end{tabular}

As can be seen from table 2, The importance rank of evaluation index as follows, the ability of self-defense, the requirements level on the airport(Kairport), dispatch out time again(Tdispatch)/h, the cruise speed(Vcruise $) /(\mathrm{km} / \mathrm{h})$, the capacity of navigation and positioning, the number of guide the aircraft to combat(nguide), the weight of other index are less than 0.1 .

The projection value of four types AWE and order as shown in table 3.

Table 3 The projection value of four type AWE and order

\begin{tabular}{|c|c|c|}
\hline index & projection value & order \\
\hline E-3F & 2.7268881 & 1 \\
\hline E-2C & 0.0220313 & 4 \\
\hline A-50 & 1.1815744 & 3 \\
\hline Phalcon & 2.2622509 & 2 \\
\hline
\end{tabular}

As can be seen from the table 3 , the evaluation four types of AWE order as follows

$$
\text { E-3F }>\text { Phalcon }>A-50>E-2 C
$$

Exactly the same as that of literature[4] sequence, it proves the rationality of the method. 


\section{Conclusion}

The projection pursuit method transforms a number of evaluation index into one-dimensional projection value by the optimal projection direction, avoiding anthropogenic interference factors of the expert score, eliminating evaluation process of the expert score, the method is more scientific, accurate and objective. In this paper, by the projection pursuit method to evaluate the operational effectiveness for the four kinds of AWE models,not only gives a comprehensive evaluation order of various types of AWE, but also gets the weight of each evaluation index. The method is easy to decision-making, very strong applicability and operability.It is of great significance to evaluate quality and management level for the AWE.

\section{References}

[1]SUN Hai-hong.ZHANG Ping-ding. Analysis on the Operational Efficiency Evaluation of Early-Warning Aircraft System, Journal of Missiles and guidance.,2004,24(3),399-341

[2]JIA Zi-ying,LI Yong, LIU Wei-dong. Evaluation of Combat Effectiveness of Early-Warning Aircraft Based on Advantage Function of System and IAHP, Journal of Naval Aeronautical and Astronautical University, Vol. 26 No.4,2011:461-463

[3]GUO Hui, XU Hao-jun, LIU Ling. Measurement of combat effectiveness of early-warning aircraft based on interval number. Systems Engineering and Electronics, Vol.32 No.5,2010:1007-1009

[4]GUO Hui, XU Hao-jun, REN Bo, CUI Lian-zhu, MENG Jie, LIU Ling. Combat Effectiveness Evaluation of AWACS Based on Fuzzy Synthetic Evaluation.Mathematics in Practics and Theory,2012,42(4):102-104.

[5]Pei Y, Effectiveness analysis and evaluation of early-warning aircraft in air-defense early-warning and intercept guidance[J]. Electronics Optics Control 2007,14(6):43-47

[6]Chen H, Lei Y J. System effectiveness analysis of AWACS on early-warning for aerial defense[J].Military Operations Research and Systems Engineering,2006,20(4);25-29

[7]Vincke P. Multicriteria decision making:advances in MCDM models, algorithms, theory and applications[M].Nether-lands; Kluwer Academic Publishers Group,1999.

[8]Lu Y Q,Wang Y I,Zhu C Y.Application of Application of TOPSIS to sequencing computation of protected important targets in area air defense [J]. Fire Control and Command Control, $2006,31(2)$ : 20-21

[9]He X Y. Hu X F. Research on method of measure the synthesis effectiveness of C4ISR[J].Systems Engineering and Electronics,2006,28(5:723-726)

[10]Wei J C, Hu X F.Modeling method of weapon system's effectiveness and its applications[J].Systems Engineering and Electronics,2002,24(6):20-24 